\title{
History
}

(c) Ponomarenko G.N., Shcherbina K.K., Smirnova L.M., Sokurov A.V., Bol’shakov V.A., Burov G.N., Kuz’menko E.I., Ermolenko T.V., Belyanin O.L., 2020

DOI 10.18019/1028-4427-2020-26-2-282-288

\section{Leningrad Research Institute for Prosthetics during the Great Patriotic war and the city blockade}

\author{
G.N. Ponomarenko, K.K. Shcherbina, L.M. Smirnova, A.V. Sokurov, V.A. Bol’shakov, G.N. Burov, \\ E.I. Kuz'menko, T.V. Ermolenko, O.L. Belyanin
}

Federal Scientific Center of Rehabilitation of the Disabled named after G.A. Albrecht, Saint Petersburg, Russian Federation

\begin{abstract}
Introduction The archives, which include 670 medical cases filed at the Leningrad Research Institute for Prosthetics (LNIIP) during the siege of the city, is unique for understanding the specific scope of medical work during the tragic time of the Great Patriotic war. The purpose of the study was to analyze the activities of the Leningrad Research Institute for Prosthetics in the besieged Leningrad during the Great Patriotic war. Methods The analysis of the LNIIP archives using the methods of content analysis, deduction, induction and synthesis was carried out. 670 cases related to the time of the Great Patriotic war were studied. Statistical data processing was performed. Results The LNIIP hospital worked as a front-line evacuation station from 01.09.1941 to 30.12.1942 and treated a total of 1,221 patients. 131 medical records of military officers and soldiers treated there during that period were found. The reason for hospitalization in $65 \%$ of those patients was the consequences of shrapnel wounds, gunshot and mine explosion injuries were less frequent. In the period from 25.05.1943 to 19.06 .1945 , there were 539 medical records of civilians. In $51 \%$ of the cases, the reason for hospitalization was shrapnel wounds, gunshot and mine explosion wounds and only $2 \%$ were pre-war cases. Discussion The nature of injuries the civilian population of the besieged Leningrad did not differ from that of the front-line soldiers. The front passed right through the besieged city, and its inhabitants were soldiers of that front. 1428 medical interventions were performed including $31 \%$ of operative plasty procedures (re-amputation, skin and bone grafting, amputation) and $32 \%$ were surgical interventions. 356 individuals were provided with prostheses, 10 with orthopedic devices, and 48 with orthopedic shoes. Preparation for prosthetic fitting was complicated by avitaminosis, dystrophy, and scurvy. The work of LNIIP in the extreme conditions of the war and blockade is a vivid example of the contribution of medical workers to the victory of the whole country. The experience of organizing a medical hospital in special conditions has not lost its relevance today.
\end{abstract}

Keywords: medical rehabilitation, Great Patriotic war, Leningrad Research Institute for Prosthetics, the siege of Leningrad, archives

\section{INTRODUCTION}

The Leningrad Research Institute for Prosthetics (hereinafter referred to as the Institute, LNIIP) was created in 1919 by the efforts of a talented surgeon and orthopaedist German Alexandrovich Albrecht at the Mariinsky Shelter, established in 1883 by Emperor Alexander III.

In 1922, the Institute opened its own prosthetic workshop and in 1928 a medical prosthetic hospital with 30 beds. The Institute turned into the All-Union Scientific and Methodological Centre which directly guided the practical work on prosthetic management and training of all categories of medical and technical specialists. The Leningrad prosthetic plant was also subordinate to the Institute.

G.A. Albrecht developed and organized a unified system of conservative and surgical preparation for prosthetic fitting, provision of prostheses, training in their use in a specialized institution with the necessary equipment, medical and technical staff. He made an invaluable contribution to the science and practice of the national prosthetics.

Unfortunately, like many ascetics, G.A. Albrecht did not pay enough attention to his health. Due to prolonged and aggressive pneumonia with relapses and a pulmonary abscess, on December 24, 1933, German Aleksandrovich died in his apartment, located in the building of LNIIP. The talented scientist and organizer left behind a new medical and technical discipline, prosthetics, in which, in the full sense of the modern understanding of this term, the technical side of prosthetics was combined with the medical and organizational issues in the interests of patients. The Institute has grown up G.A. Albrecht's successors: professors T.M. Stepanov, M.S. Yusevich and Honored Doctor of the RSFSR V.A. Betekhtin. To the beginning of World War II, the Institute had gained invaluable experience in helping the wounded during the war with Finland from 1939 to 1940. In a statistical study, it is stated that, about 3.8 million people were demobilized during the Great Patriotic War due to illness, injury and age, of which 2.5 million were disabled [1]. Among them, 460 thousand persons sustained amputation of the upper and / or lower limbs.

According to archival data, during the war years, 1221 wounded and sick persons passed an average term of about three months at the LNIIIP hospital [2]. We do not have all the materials of the Institute related to its work in the historical

迥 Ponomarenko G.N., Shcherbina K.K., Smirnova L.M., Sokurov A.V., Bol'shakov V.A., Burov G.N., Kuz'menko E.I., Ermolenko T.V., Belyanin O.L. Leningrad Research Institute for Prosthetics during the Great Patriotic war and the city blockade. Genij Ortopedii, 2020, vol. 26, no 2, pp. 282-288. DOI 10.18019/1028-4427-2020-26-2-282-288 
period under this study. Nevertheless, even the available Institute's archive, that contains 670 case reports from the first days of the siege of Leningrad to the end of World War II, has a unique particular value and allows us to understand the specifics and scope of the Institute's work in those tragic times.

The purpose of the article was to analyze the activities of the Leningrad Research Institute for Prosthetics during the Great Patriotic War and the siege of Leningrad.

\section{MATERIAL AND METHODS}

The work is the result of the analysis and statistical processing of a part of the archives of the Leningrad Scientific Research Institute for Prosthetics related to wartime and stored at the Federal Scientific Centre for the Rehabilitation of Persons with Disabilities named after G.A. Albrecht of the Ministry of Labor and Social Protection of the Russian Federation.

670 medical records of patients aged from seven to 97 years (131 military servicemen and 539 civilians) who were admitted to the LNIIP clinic from 01.10.1941 to 19.06.1945 along with archival reports were analyzed.
According to the first digit of a four-digit number, the records were divided into three groups: " $1 \mathrm{XXX}$ ", " $4 \mathrm{XXX",}$ " $5 \mathrm{XXX}$ ". The medical reports " $1 \mathrm{XXX"}$ and "4XXX" were filed from 01.10 .1941 to 01.10 .1942 and refer only to male servicemen and four employees of the Institute who underwent therapeutic treatment for grade 2 dystrophy. The 5XXX medical cases were filed from 25.05.1943 to 19.06.1945 and apply only to civilian patients.

Research methods were content analysis; deduction, induction and synthesis; methods of statistical data analysis.

\section{RESULTS}

Although, according to the archival data for the war years, 1221 wounded and sick persons were admitted to the LNIIIP hospital, only 670 medical records of that time were preserved and thus could be analyzed. It is noteworthy that no deaths were reported in them. Probably, the deaths were documented and stored separately from the rest of files or were transferred to other institutions. Perhaps, this explains the fact of missing cases.

The most numerous admission of servicemen to the LNIIIP hospital was observed in October 1941 (38 patients), and of civilians in May 1944 (49 patients) (Fig. 1). At at the beginning of the war, due to a large number of military persons hospitalized, the admission of civilian population was temporarily stopped and was resumed only in 1943 after breaking the blockade of Leningrad [2].

The war set organizational and methodological tasks before the Institute's specialists, different from the peacetime, to deploy in a short period of time a sufficient number of beds at this front-line evacuation centre. The wounded were rendered specialized surgical, prosthetic and orthopedic care.

Already in the prewar years, the Institute gained experience in prosthetic management after injuries and combat trauma. Innovative for that time technical solutions and medical treatment methods were developed. Halfextremity prosthesis without a socket (cuff) on the thigh which achieved an additional functional and esthetic effect was designed (Ya.I. Lurie, 1935; V.A. Betekhtin, 1936; M.S. Yusevich, 1940); prosthetic foot, the so-called "Leningrad type", was created; lightweight nitro-lacquer orthopedic devices, braces and stump sockets were proposed instead of heavy leather and wooden structures; the tested in 1926-1927 manufacturing technology of "deep" lower leg prostheses with the capture of the femoral condyles which is most beneficial for short stumps was resumed. It was of great importance for prosthetic fitting after amputation due to military injuries with the presence of characteristic diseases and malformations of the stump. The technology of reconstructive interventions on the stumps based on the results of a study that investigated the morphology and anatomy of the stump was proposed. The necessity of staged surgical treatment of the wounded, their referral after limb amputation to large medical institutions adapted for those in need of prosthetic and orthopedic supplies, was substantiated.

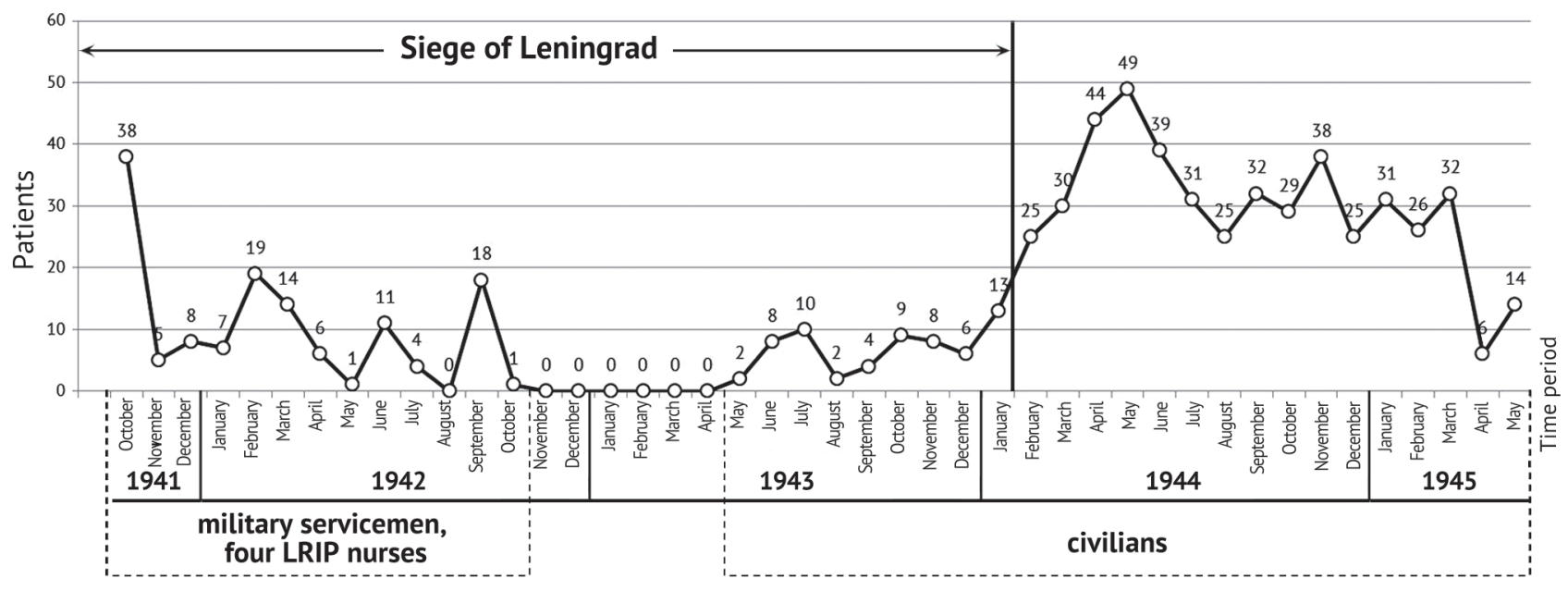

Fig. 1 Dynamics of patient admission to the Leningrad Research Institute for Prosthetics 
The outbreak of the Great Patriotic war was accompanied by innumerable calamities of the Leningrad Blockade. However, the remaining small group of doctors (V.A. Betekhtin, P.I. Belousov, A.N. Vitkovskaya, L.D. Schwindt), nurses and junior staff continued with the Institute's activities in extremely difficult conditions of the besieged city (Fig. 2).

In the period from 1 September 1941 to 30 December 1942, a front-line evacuation point No. 50 (FEP No. 50) was organized at the Institute's hospital with 110 beds for the wounded transported from the front. As evidenced by the recollections of the employees of the Institute at the wartime, changes in premises had to be done to increase the number of beds.

It was necessary to support the work of the hospital under constant bombing and shelling, despite interruptions in the supply of medicines, in the conditions of damage to the Institute's building, its communications and equipment by the enemy. According to the Commission Act dated 06.06.1943, the facts of a complete destruction of the roof of the main building, $30 \%$ of the electrical wiring, water and sewer networks, $5 \%$ of the stock of heating furnaces were registered. The employees closed with plywood and cardboard the holes on the ceiling and walls from shelling, broken by a blast wave glass in the window frames which made the work more difficult in the absence of kerosene and oil for lighting. The temperature in the wards, the dressing room and the operating room that was arranged in a small reception room without windows sometimes dropped to $0{ }^{\circ} \mathrm{C}$. The laundry was completely ruined. Moreover, the bed linen and hospital clothes sent to the laundry of the Gorkommunotdel for washing were destroyed during the bombing. Disinfection of linen and things was not possible. The same document of the Commission estimated the total loss at 189,700 rubles.

Due to hunger and shelling, there were casualties among employees and patients. Institute employees V.E. Demidov, N.V. Draeger, A. Ershov, A.A. Zagadkin, I.P. Kovalev, P.A. Mikutsky, A.N. Nikitin, O.V. Pavlov, A.A. Khotsin, V.N. Chimorsky died in the besieged Leningrad.

Despite the difficulties and obstacles, the team headed by the director of the Institute, Dr. V.A. Betekhtin, when asked about the closure of the hospital, made a courageous decision to continue and increase the work of providing surgical, prosthetic and orthopedic care to war invalids.

In 1941-1942 for obvious reasons, the work of the Institute was limited mainly to emergency interventions.

Upon the patient's admission to the Institute's hospital, an attending doctor, a nurse or even a specially trained staff officer completed the main document, the medical case report, sometimes using just paper that was at hand instead of special typographic forms.

Before the war, the Institute had the status of an advanced scientific centre with the staff of outstanding scientists. But when the war began, most of the Institute's staff, both doctors and technical workers, were mobilized into the Red Army. Graduate and college students' courses were accelerated; advanced training courses for prosthetics specialists were canceled. According to the reports of the Director of the Institute V.A. Betekhtin, the permanent staff was composed of only three out of eight graduate students, one of two residents, one of five researchers, five of 18 doctors, and two of 11 nurses. The rest of the personnel often changed. Some highly skilled craftsmen at the prosthetic plant died.

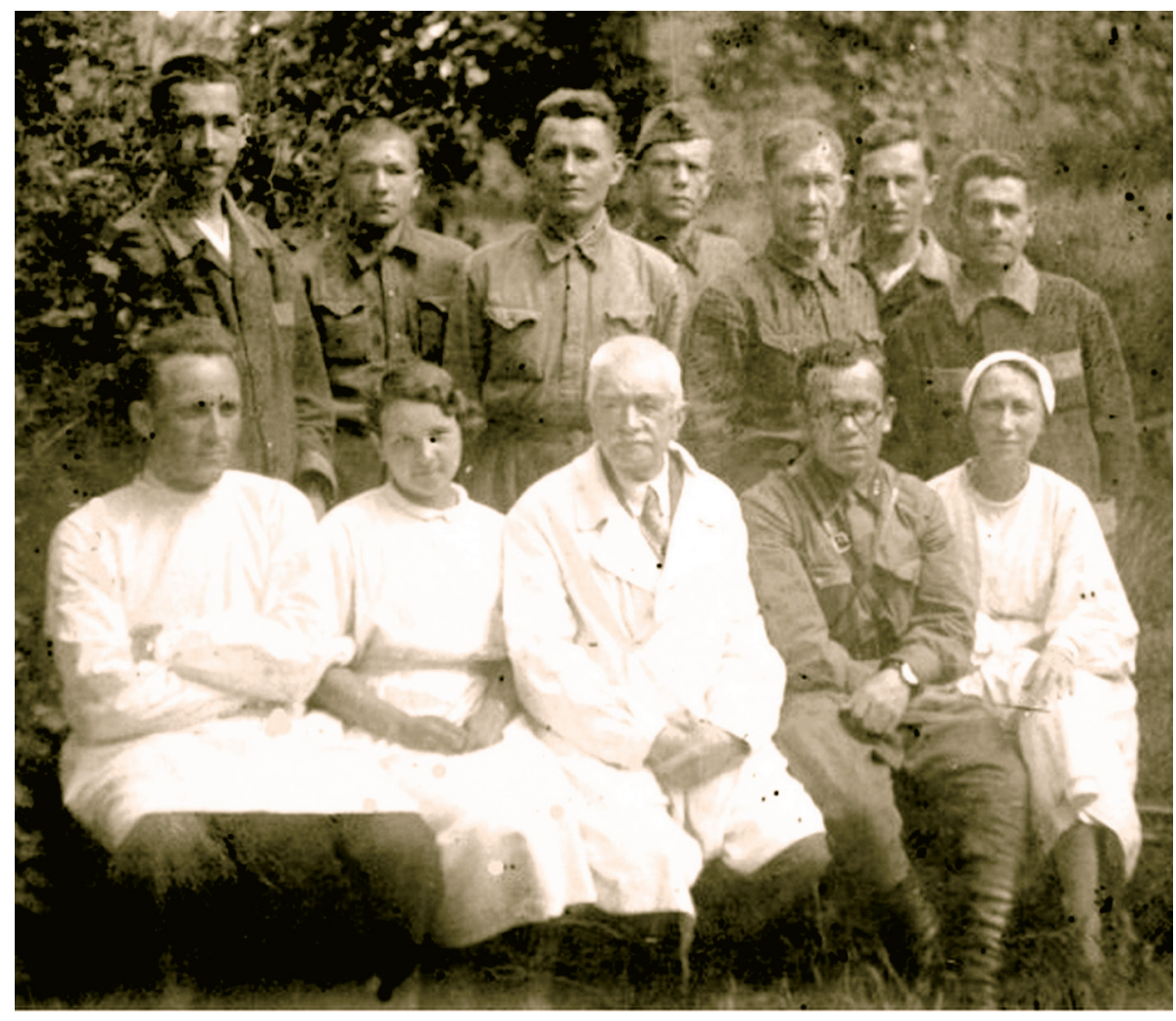

Fig. 2 LNIIP team and representatives of the Red Army in 1943 (first row from left to right, doctors Belousov P.I. and Vitkovskaya A.N., director of the Institute V. Betekhtin, representative of the Red Army, doctor Shvindt L.D.) 
Neither hunger, nor painful condition and dystrophy prevented the LNIIP staff from performing other necessary life support tasks such as carrying water from the Neva, sawing wood and heating stoves, evacuating patients in the bomb shelter of the prosthetic plant until the enterprise was destroyed as a result air raid. In some periods, round-the-clock 18-20-day shifts fell on the shoulders of only one doctor due to severe dystrophy of the remaining senior medical personnel.

In addition to active work in providing specialized assistance and prosthetic treatment for the wounded, in the difficult conditions of the hospital, under bombardment and shelling, the employees of the Institute, who were starving and freezing, consulted patients in other Leningrad hospitals, trained prosthetic specialists, continued scientific work, made presentations in military hospitals and at the surgical society named after N.I. Pirogov. In the besieged conditions of 1941, the Institute issued the eleventh collection of scientific works "Issues of Prosthetics" of 18.5 printed pages with a circulation of 700 copies, containing 29 scientific works owned by 18 authors. Five scientific conferences, 7 reports, 6 patient demonstrations, 5 discussions on scientific topics were held.

Based on the experience of the medical service at the beginning of the war, scientific provisions on the levels of amputations were revised: the need was determined not according to previously accepted schemes (pre-war), but, first of all, by the location and nature of the damage, threat of infection, place and conditions of amputation, and general condition of the patient. The priority of osteoplastic operations with the formation of stumps after amputation according to Pirogov was justified in comparison with amputations according to Biru and Gritti, which were widely practiced before the war, but allowed to achieve only weight-bearing in the long term due to pathological changes in the soft tissues of the end of the stump.

In addition to the wounds and burns received during shelling and bombing, many patients had exhaustion and dystrophy. The lack of nurses was filled up by students of medical institutes and schools.

131 medical records were discovered dated to the period between 01.10 .1941 and $01.10 .1942,127$ military servicemen (112 ordinary soldiers and sergeants, 15 offices) and 4 employees of LNIIIP with severe dystrophy. On some days of the work of the front-line evacuation point, there was a particularly large admission of wounded soldiers. For example, on 10 January 1941, 16 cases were registered, but the difference between the minimum and maximum numbers of these documented files is 24 , which allows us to conclude that at least 8 more people were accepted on this day. Perhaps the medical records of some of them did not appear on the list of the discharged from the hospital due to death.

The Institute focused its work on surgical care for servicemen coming directly from the front. Conservative and operative preparation for prosthetic fitting continued. Amputation, re-amputation, bone and skin grafting, and reduction of bone fragments were performed. There was also a therapeutic and physiotherapeutic treatment. 115 military servicemen $(91 \%)$ ended treatment being supplied with prostheses of the upper and / or lower limbs.

The age of these patients was in the range from 17 to 53 years with a median value of 29 years and the values of the first quartile of the parameter distribution - 24 years and the third -35 years old (Fig. 3 ).

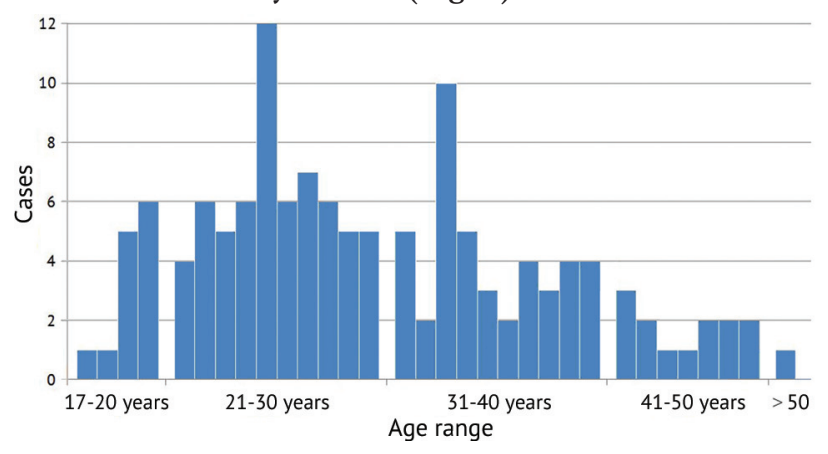

Fig. 3 Age distribution of military servicemen at the LNIIIP hospital in the period from 01.10.1941 to 01.10.1942

Of these, $54 \%$ of servicemen lived in Leningrad and the Leningrad region, about a third in other settlements of the RSFSR, and $7 \%$ in other Soviet republics (Fig. 4).

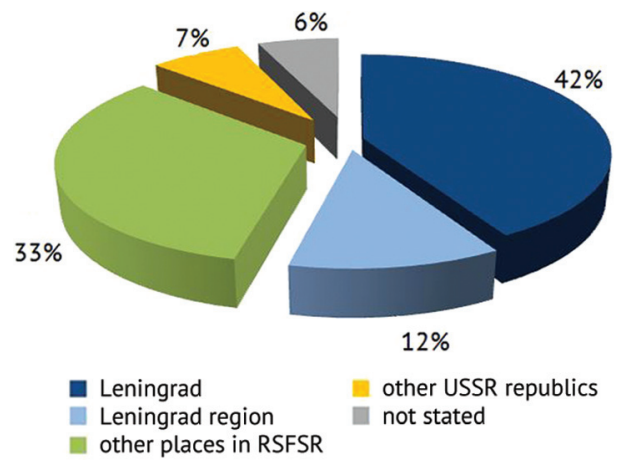

Fig. 4 Distribution according to a residence place of the servicemen treated in the LNIIP hospital in the period from 01.10.1941 to 01.10 .1942

The most frequent cause of servicemen hospitalization was shrapnel wound sequelae followed by gunshot and mine injuries (Fig. 5). Combined trauma was a cause in several cases.

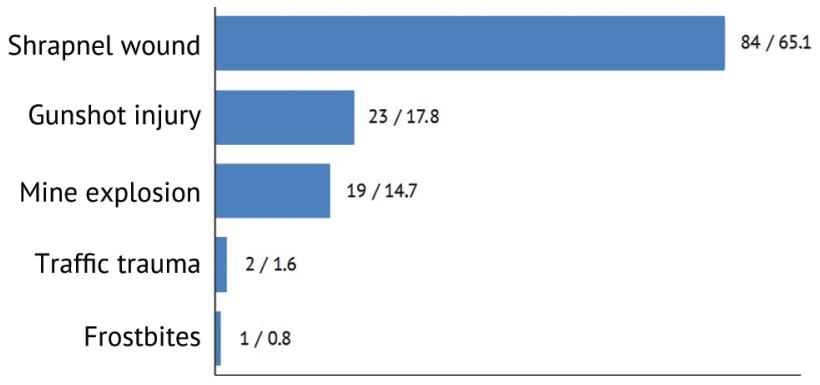

Number of cases / \%

Fig. 5 Distribution according to injury cause in military servicemen at the hospital of LNIIIP in the period from 01.10 .1941 to 01.10 .1942

As follows from the analysis of the historical cases, preparation for prosthetic fitting were complicated by 
concomitant vitamin deficiency, dystrophy, scurvy; nothing, except for the coniferous extract obtained from the distillery factory located near the Institute, was available to treat them with. By 1942, some of the remaining doctors had extreme exhaustion, were not able to continue working and had to leave the Institute.

The beginning of 1943 was characterized by significant successes of the Red Army at the front. The blockade of Leningrad was broken on 18.01.1943, and the capitulation of the northern group of German troops ended the Battle of Stalingrad on 02.02.1943. By that time, the work of the railway was resumed. The conditions for the evacuation of wounded servicemen to the interior of the country were facilitated.

By the order of the city health department, the medical service to the civilian population was resumed from the beginning of 1943. The Institute's working conditions gradually improved. The X-ray room and physiotherapy department were reopened, the water supply and sewage systems were restored. The nutrition of patients and hospital staff improved.

As a result of the first of ten "Stalin's attacks", the blockade of Leningrad was broken on 27.01.1944. Undoubtedly, the possibilities for civilian patients to be admitted to the LNIIP hospital increased (see Fig. 1).

539 reports of medical cases were preserved from that period (25.05.1943 - 19.06.1945). Almost all of them belong to civilians. Their median age was 29 years, with the first quartile of the parameter distribution being 21 years old and the third being 37 years old (Fig. 6).

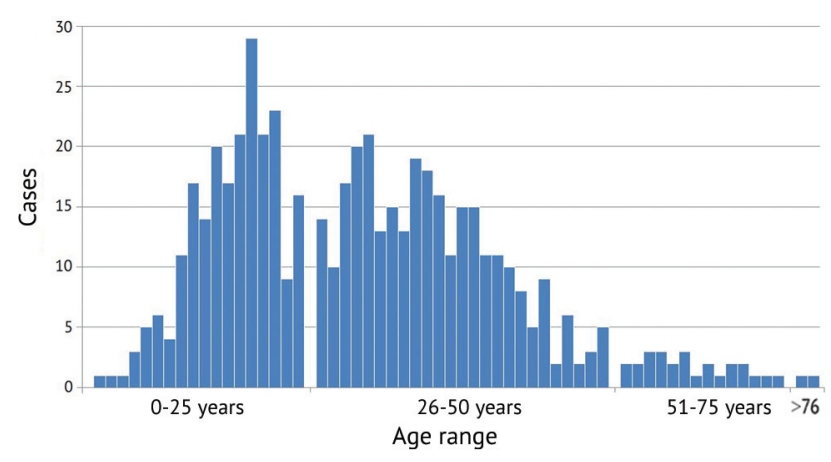

Fig. 6 Age distribution of patients at the LNIIIP hospital in the period from 25.05.1943 to 19.06.1945

The youngest patient from the available database of that period was a seven-year old boy, Arkhipov Tolya, from the Leningrad region, who underwent amputation of the foot and subsequent prosthetic fitting. The oldest patient at the time of admission to the Institute's hospital was a 97-year old Sangaevsky Vincent Lyudovikovich, a disabled pensioner (a former fireman), who was thrown by a blast wave under the vehicle on 6 September 1942 . The result of the injury was the amputation of the lower leg. Six months later (06.07.1943), the patient needed re-amputation of the lower leg, and eight months later (10.03.1944) he was provided with a lower leg prosthesis with a socket on the thigh.
More than two thirds of the surviving medical records of the civilians (379 people, $70 \%$ ) belonged to males. Of these, $79 \%$ of patients were residents of Leningrad and the Leningrad region (Fig. 7).

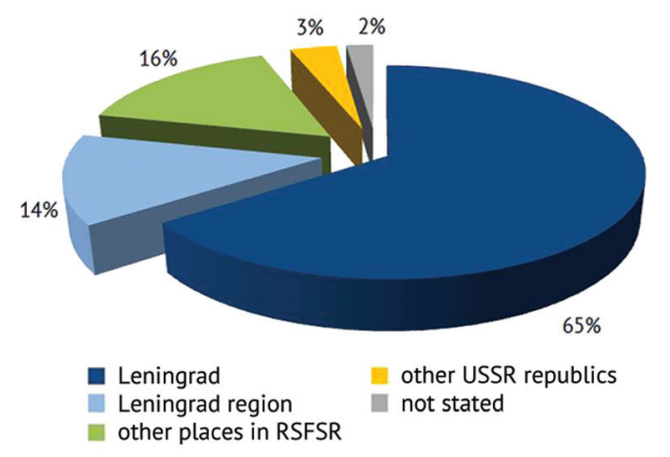

Fig. 7 Distribution according to residence place of the civilians treated in the LNIIP hospital in the period from 25.05.1943 to 19.06 .1945

The types of trauma in the civilian population (Fig. 8) are indicated in the same sequence as for military persons (Fig. 5) for a more visual comparison of these two groups. In the overwhelming majority of cases, the cause of referral of civilians to the hospital was shrapnel wounds (277 cases, $51 \%$ ), gunshot wounds were than five times less likely. Mine blasting and injuries due to road traffic accidents were somewhat more frequent. Hospitalization for frostbite, burns and crushed body segments was rare. Only in twelve people out of 539 (2\%), the cause of treatment and prosthetic and orthopedic provision was the pathology diagnosed in the pre-war period.

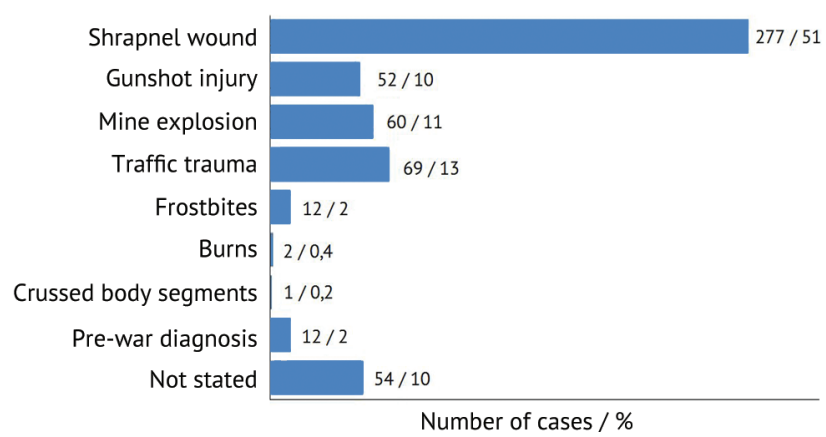

Fig. 8 Injury causes in patients at the hospital of LNIIIP in the period from 25.05.1943 to 19.06.1945

During the war period, the largest number of patients was admitted to the hospital in 1944. It may be explained both by the consequences of fierce battles to lift the blockade of Leningrad and by the increased supplies to the hospital and its greater capacity (Fig. 1, 9). The survived part of medical cases shows a large volume of medical interventions performed at the hospital, despite the military blockade time.

The patients of the hospital underwent complex treatment by various types of medical interventions, including therapeutic and physiotherapeutic treatment. Most of the patients had surgical plasty procedures (444 medical records out of 670 or $31 \%$ of the total 
number of 1428 interventions) and surgical interventions (455 medical records, $32 \%$ of interventions) (Fig. 10).

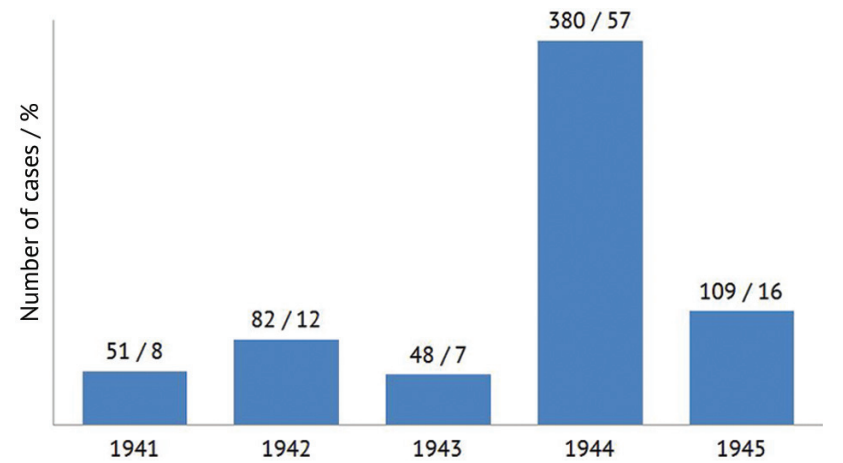

Fig. 9 Distribution of patients admitted to the hospital LNIIP by years

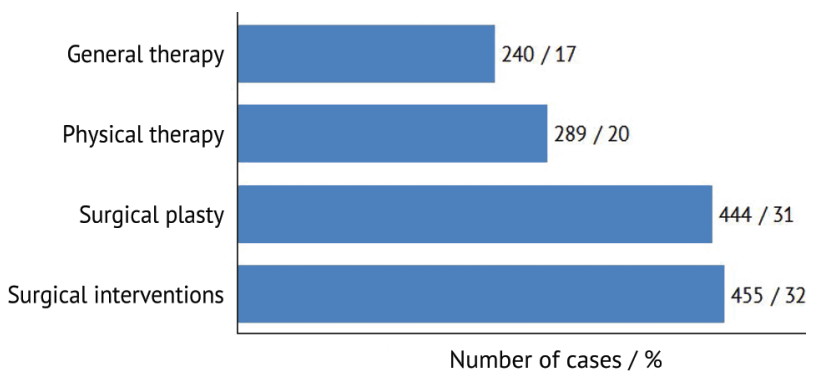

Fig. 10 Medical interventions in patients of the LNIIP hospital in the period from 01.10.1941 to 19.06.1945

Moreover, re-amputation significantly prevailed among the plastic operations. They were performed in 257 out of 670 patients, or $58.3 \%$ of the total number of operations (Fig. 11). Skin grafting (126 people or $28.6 \%$ of the total operations) was less common, bone grafting and amputations even less frequent (29 people and 28 people, respectively, which corresponds to 6.6 and $6.3 \%$ of the medical interventions performed in the hospital). Vascular plastic surgery was one case.

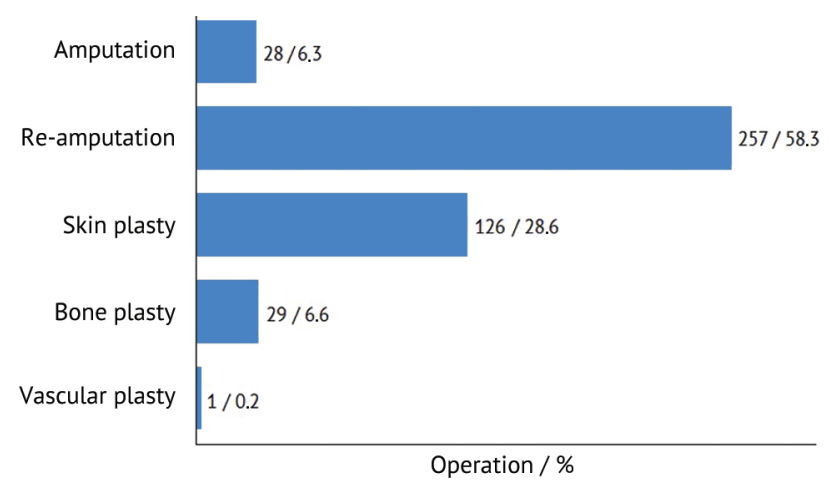

Fig. 11 Types of operations in patients of the LNIIP hospital in the period from 01.10.1941 to 19.06 .1945

During this period, according to cases available, 356 patients (53\%) were supplied with prostheses, 10 patients $(1.5 \%)$ with orthopedic devices, and 48 patients (7 \%) with orthopedic shoes. Moreover, many of those patients received prosthetic and orthopedic management in more than one limb. Thus, prosthetic and orthopedic care was rendered for a total of $61.5 \%$ of patients at the LNIIP hospital.

Statistics on amputation show that truncations of the lower limb were found several times more frequent than of the upper limbs (Fig. 12). A particularly high proportion of limb truncation was at the tibia level. In the servicemen who were injured at the front, they accounted for $43 \%$ of all amputations. In civilians, this number was even higher, 50 $\%$. Femur amputations were a little less common. Moreover, the portion of severe combined amputation, either both lower and upper limbs, was even higher among the civilian population than that of the military.

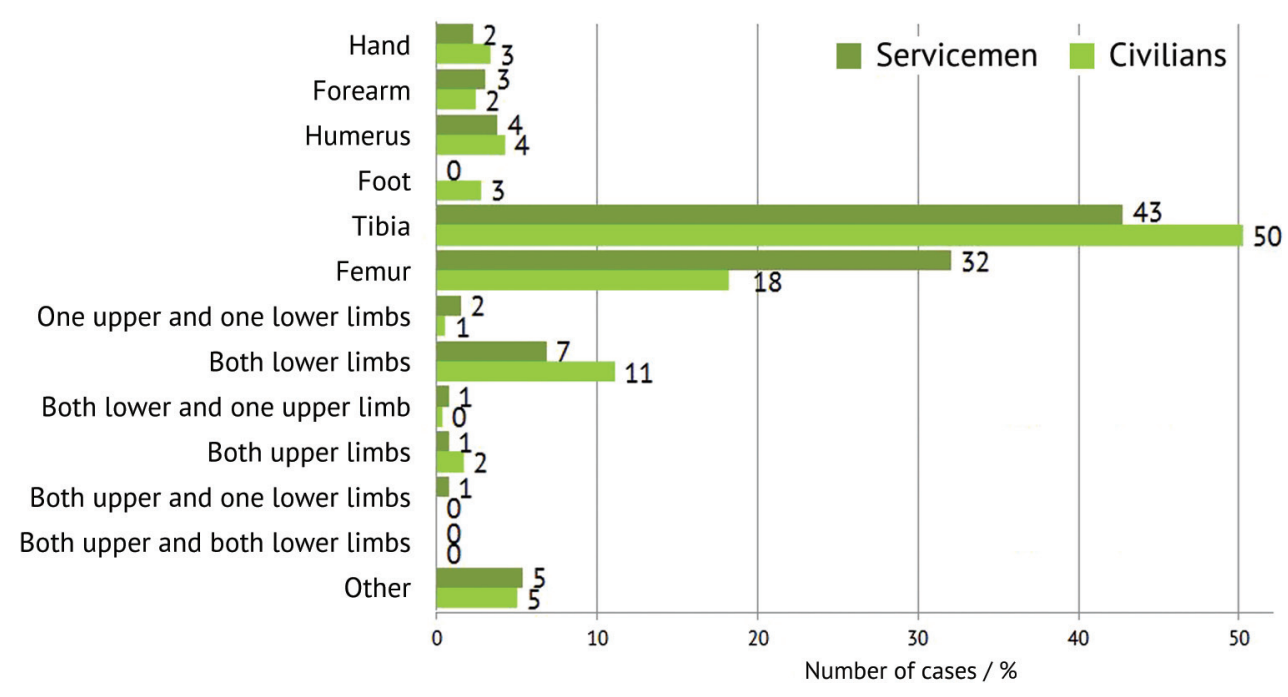

Fig. 12 Distribution of patients at the LNIIIP hospital according to limb truncation

\section{DISCUSSION}

The archive does not contain all the cases that passed through the hands and were cared by the specialists of the Leningrad Research Institute for Prosthetics during the wartime. We could not find the medical record of the pilot fighter Leonid Georgievich Belousov who lost both legs (at the level of the thigh and lower leg) during the Great Patriotic War, had prosthetic fitting at the Institute's hospital, returned to duty, continued to fly and 
participate in battles. His autograph with the words "To the Leningrad Research Institute for Prosthetics that has helped me to return in the rows of fighters" Commander of Squadron Ganguttsev, Hero of the Soviet Union L.G. Belousov, 22.12.1969" left in the book "The Man of Highest Valor and Heroism" by a writer J.F. Potekhin about L.G. Belousov and kept at the museum of the FSBI G.A. Albrecht Federal Research Centre of the Ministry of Labor of Russia reminds that time.

Prosthetic orthopedic care was provided to $61.5 \%$ of patients at the LNIIP hospital.

The statistics of the cases show that with the same median age ( 29 years) in the groups of patients, both military and civilians, that were admitted to the LNIIP hospital in the wartime, the age range of the civilians was significantly wider. However, the nature of the injuries in the civilian population of the besieged Leningrad did not differ from the military officers and soldiers of the front. In both groups, truncations of the lower limb were several times more common compared with the upper limb. A particularly high proportion of them were amputations at the level of the lower leg, slightly less frequent at the level of the thigh. This applies both to servicemen who were injured at the front and to civilians from the besieged city. Moreover, the number of severe combined amputations of either both lower limbs or both upper limbs at the same time among the civilian population was even higher than of the military persons.

These results are a vivid illustration of the fact that the front went straight through the besieged city, and its inhabitants were soldiers of that front.

\section{CONCLUSIONS}

The work of LNIIIP staff during the Great Patriotic War is a bright example of the contribution of medical workers to the common Victory.

The activity of the LNIIIP hospital was organized in the extreme conditions of the war and blockade. Even in the conditions of a shortage of personnel and resources, significant results were achieved in training and prosthetic management of both military servicemen and civilians. The experience of organizing the work of a medical hospital in special conditions has not lost its relevance in our days.

Sources of funding: state budget

Conflict of Interest: None

\section{REFERENCES}

1. Poteri Vooruzhennykh Sil: statisticheskoye issledovaniye [The casualties of the Armed Forces: a statistical study]. Colonel General Krivosheev G.F., ed. M., Olma-press, 2001, 608 p. (in Russian)

2. Ponomarenko G.N., Bolshakov V.A. Federalnyy nauchnyy tsentr reabilitatsii invalidov imeni G.A. Albrekhta - stranitsy istorii [Federal Scientific Center for the Rehabilitation of Disabled People named after G.A. Albrecht - pages of history]. SPb., LLC TsIATsAN, 2018, 180 p. (in Russian)

Received: 21.04.2020

Information about the authors:

1. Gennadiy N. Ponomarenko, M.D., Ph.D., Professor, Honored worker of science of the Russian Federation, Federal Scientific Center of Rehabilitation of the Disabled named after G.A. Albrecht, North-Western State Medical University named after I.I. Mechnikov, Saint Petersburg, Russian Federation, Email: ponomarenko_g@mail.ru, http://orcid.org/0000-0001-7853-4473

2. Konstantin K. Shcherbina, M.D., Ph.D., Federal Scientific Center of Rehabilitation of the Disabled named after G.A. Albrecht, Saint Petersburg, Russian Federation, Email: shcherbina180@mail.ru, http://orcid.org/0000-0001-7579-0113

3. Ludmila M. Smirnova, Ph.D. of Engineering Sciences, Professor, Federal Scientific Center of Rehabilitation of the Disabled named after G.A. Albrecht, Saint Petersburg, Russian Federation, Email: info@diaserv.ru, http://orcid.org/0000-0003-4373-9342

4. Andrei V. Sokurov, M.D., Ph.D., Federal Scientific Center of Rehabilitation of the Disabled named after G.A. Albrecht, Saint Petersburg, Russian Federation, Email: ansokurov@yandex.ru, http://orcid.org/0000-0002-3736-2895
5. Vladimir A. Bol'shakov, Federal Scientific Center of Rehabilitation of the Disabled named after G.A. Albrecht, Saint Petersburg, Russian Federation, Email: pko09_903@mail.ru, https://orcid.org/0000-0002-5889-3759

6. Gennadiy N. Burov, Ph.D. of Engineering Sciences, Federal Scientific Center of Rehabilitation of the Disabled named after G.A. Albrecht, Saint Petersburg, Russian Federation, Email: zxzy@yandex.ru;

7. Elena I. Kuz'menko,

Federal Scientific Center of Rehabilitation of the Disabled named after G.A. Albrecht, Saint Petersburg, Russian Federation, Email: lenochk51@mail.ru;

8. Tatiana V. Ermolenko, M.D., Ph.D., Federal Scientific Center of Rehabilitation of the Disabled named after G.A. Albrecht, Saint Petersburg, Russian Federation, Email: tatvalerm@yandex.ru, http://orcid.org/0000-0002-3903-5417

9. Oleg L. Belyanin,

Federal Scientific Center of Rehabilitation of the Disabled named after G.A. Albrecht, Saint Petersburg, Russian Federation, Email: belynin.oleg41@bk.ru 